\title{
Chapter 22 \\ Modification of the STACY Critical Facility \\ for Experimental Study on Fuel Debris \\ Criticality Control
}

\author{
Hiroki Sono, Kotaro Tonoike, Kazuhiko Izawa, Takashi Kida, \\ Fuyumi Kobayashi, Masato Sumiya, Hiroyuki Fukaya, Miki Umeda, \\ Kazuhiko Ogawa, and Yoshinori Miyoshi
}

\begin{abstract}
For the decommissioning of the Fukushima Daiichi Nuclear Power Stations, fuel debris involving molten structural materials should be retrieved from each reactor unit. The fuel debris, which is of uncertain chemical composition and physical state, needs to be treated with great care from the standpoint of criticality safety. For developing criticality control for the fuel debris, the Japan Atomic Energy Agency (JAEA) has been planning to modify the Static Experiment Critical Facility (STACY) and to pursue critical experiments on fuel debris. STACY, a facility using solution fuel, is to be converted into a thermal critical assembly using fuel rods and a light water moderator. A series of critical experiments will be conducted at the modified STACY using simulated fuel debris samples. The simulated fuel debris samples are to be manufactured by mixing uranium oxide and reactor structural materials with various chemical compositions. This report summarizes a facility development project for an experimental study on criticality control for fuel debris using the modified STACY and simulated fuel debris samples.
\end{abstract}

Keywords Critical facility • Criticality control $\bullet$ Criticality safety $\bullet$ Fuel debris - Fukushima Daiichi • Simulated fuel debris sample • STACY

\subsection{Introduction}

In the severe accident at the Fukushima Daiichi Nuclear Power Stations (NPS), most of the fuel loaded in the cores of Units 1, 2, and 3 was seriously damaged and melted, resulting in a considerable amount of fuel debris [1]. It is believed that some parts of the fuel debris involve molten structural materials such as zircaloy, stainless steel, and concrete. This fuel debris, which contains much burned fuel,

H. Sono $(\bowtie) \bullet$ K. Tonoike $\bullet$ K. Izawa $\bullet$ T. Kida $\bullet$ F. Kobayashi $\bullet$ M. Sumiya

H. Fukaya $\bullet$ M. Umeda $\bullet$ K. Ogawa $\bullet$ Y. Miyoshi

Japan Atomic Energy Agency, Tokai-mura, Naka-gun, Ibaraki, 319-1195, Japan

e-mail: sono.hiroki@jaea.go.jp 
still continues to emit radiation and heat. For decommissioning of the Fukushima Daiichi NPS, all the fuel debris should be retrieved from the pressure and containment vessels of each reactor unit.

In preparation for retrieval of the fuel debris from the Fukushima Daiichi NPS, however, there remain the following serious problems: (1) leakage of cooling water from containment vessels, (2) inflow of groundwater into reactor buildings, (3) maintenance of subcritical state of the fuel debris, and (4) shielding of radiation from the fuel debris [2]. The cooling water of the fuel debris concerns these four problems. In a similar accident that occurred at Three Mile Island NPS Unit 2 (TMI-2), where its pressure vessel was not seriously damaged, all these problems were settled or did not arise because the pressure vessel could be filled with cooling water containing highly concentrated boron as a neutron absorber and radiation shield [3]. In contrast, all four problems make it extremely difficult to retrieve the fuel debris from each reactor unit of the Fukushima Daiichi NPS.

The fuel debris, which has uncertain chemical composition and physical state, needs to be treated with great care from the aspect of criticality safety. In particular, large blocks of fuel debris can cause a change in physical state, such as size and water content, when they are broken into fragments to be retrieved in cooling water. Furthermore, a recent study on fuel debris resulting from the molten core-concrete interaction has revealed its potential for criticality [4]. There will probably be no risk of a criticality accident if it is possible to keep a high concentration of boron in the cooling water and take the criticality control measures that were used in the TMI-2 accident. However, these measures will be difficult unless both (1) the leakage of cooling water and (2) the inflow of groundwater are completely stopped. If not, retrieval of the fuel debris will require alternative approaches to criticality control in cooling water or dry retrieval with radiation shielding.

The authors focus on the former approach: new criticality control measures for fuel debris, such as criticality safety standards and criticality monitoring methodology [5]. This report summarizes a facility development project for an experimental study on criticality control for fuel debris.

\subsection{Experimental Study on Criticality Control for Fuel Debris}

\subsubsection{Modification of STACY}

To implement the new criticality control measures for fuel debris, the Japan Atomic Energy Agency (JAEA) has been carrying a project to modify the Static Experiment Critical Facility (STACY) to pursue critical experiments on fuel debris [6]. STACY, a facility using solution fuel (low-enriched uranyl nitrate), is to be converted into a thermal critical assembly using fuel rods and a light water moderator. 
In the modified STACY, the core configuration consists of fuel rods loaded in the core tank (up to 900 rods) and light water fed as moderator. Because the maximum thermal power is only $200 \mathrm{~W}$, fuel burn-up is negligibly small and cooling water is unnecessary. The reactivity of the core is controlled not with control rods but by water level, and with safety plates (cadmium) in the case of emergency shutdown, similar to the present STACY. The fuel rods contain $5 \mathrm{wt}$.\%-enriched $\mathrm{UO}_{2}$ pellets and have zircaloy cladding. A soluble neutron poison (boron) can be added to the light water moderator. Major core specifications and a schematic diagram of the modified STACY are shown in Table 22.1 and Fig. 22.1, respectively.

Table 22.1 Major core specifications of the modified Static Experiment Critical Facility (STACY)

\begin{tabular}{|c|c|c|c|}
\hline \multicolumn{2}{|l|}{ Item } & Present STACY & Modified STACY \\
\hline \multirow{2}{*}{\multicolumn{2}{|c|}{ Core tank }} & Closed tank & Open tank \\
\hline & & $\begin{array}{l}\text { Replaceable (cylinder, slab, hetero- } \\
\text { geneous, interaction) }\end{array}$ & $\begin{array}{l}\text { Cylinder ( } 1.8 \mathrm{~m} \text { in diameter, } \\
1.9 \mathrm{~m} \text { in height })\end{array}$ \\
\hline \multirow{2}{*}{\multicolumn{2}{|c|}{ Core size }} & Same as each core tank & Maximum $60 \mathrm{~cm} \times 90 \mathrm{~cm}$ \\
\hline & & Critical height $40-140 \mathrm{~cm}$ & Critical height $40-140 \mathrm{~cm}$ \\
\hline \multicolumn{2}{|c|}{$\begin{array}{l}\text { Maximum thermal } \\
\text { power }\end{array}$} & $200 \mathrm{~W}$ & $200 \mathrm{~W}$ \\
\hline \multicolumn{2}{|c|}{$\begin{array}{l}\text { Maximum integrated } \\
\text { power }\end{array}$} & $\begin{array}{l}100 \mathrm{~W} \cdot \mathrm{h} / \text { operation, } 300 \mathrm{~W} \cdot \mathrm{h} / \text { week, } \\
3 \mathrm{~kW} \cdot \mathrm{h} / \text { year }\end{array}$ & $\begin{array}{l}100 \mathrm{~W} \cdot \mathrm{h} / \text { operation, } \\
300 \mathrm{~W} \cdot \mathrm{h} / \text { week, } 3 \mathrm{~kW} \cdot \mathrm{h} / \text { year }\end{array}$ \\
\hline \multirow[t]{5}{*}{ Fuel } & Fuel solution & $\begin{array}{l}6-, 10 \mathrm{wt} . \% \text {-enriched uranyl nitrate } \\
\text { solution }\end{array}$ & \multirow[t]{2}{*}{ Not used } \\
\hline & $\begin{array}{l}\text { Maximum } \\
\text { concentration }\end{array}$ & $500 \mathrm{gU} / 1$ & \\
\hline & Fuel rods & 5 wt. $\%$-enriched $\mathrm{UO}_{2}$ pellets & $\begin{array}{l}5 \text { wt. } \% \text {-enriched } \mathrm{UO}_{2} \text { pellets } \\
(<10 \text { wt.\% available })\end{array}$ \\
\hline & Cladding & $\begin{array}{l}\text { Zircaloy cladding }(9.5 \mathrm{~mm} \text { in diam- } \\
\text { eter, } 150 \mathrm{~cm} \text { in length })\end{array}$ & $\begin{array}{l}\text { Zircaloy cladding ( } 9.5 \mathrm{~mm} \text { in } \\
\text { diameter, } 150 \mathrm{~cm} \text { in length) }\end{array}$ \\
\hline & $\begin{array}{l}\text { Maximum } \\
\text { loading }\end{array}$ & 400 rods & 900 rods \\
\hline \multicolumn{2}{|c|}{$\begin{array}{l}\text { Volume ratio of mod- } \\
\text { erator to fuel (lattice } \\
\text { pitch of fuel rods) }\end{array}$} & $1.9-15(13.0-29.0 \mathrm{~mm})$ & $0.9-11(10.9-25.5 \mathrm{~mm})$ \\
\hline \multicolumn{2}{|c|}{ Moderator } & Solution fuel & Light water \\
\hline \multicolumn{2}{|c|}{ Temperature } & Room temperature $\sim 40^{\circ} \mathrm{C}$ & Room temperature $\sim 70^{\circ} \mathrm{C}$ \\
\hline \multicolumn{2}{|c|}{ Reactivity control } & Solution level & Water level \\
\hline \multirow{2}{*}{\multicolumn{2}{|c|}{$\begin{array}{l}\text { Maximum excess } \\
\text { reactivity }\end{array}$}} & 0.2 dollar in normal operation & 0.3 dollar in normal operation \\
\hline & & 0.8 dollar in abnormal transient & 0.8 dollar in abnormal transient \\
\hline \multicolumn{2}{|c|}{$\begin{array}{l}\text { Maximum reactivity } \\
\text { addition rate }\end{array}$} & 3 cent $/ \mathrm{s}$ & 3 cent $/ \mathrm{s}$ \\
\hline \multirow{2}{*}{\multicolumn{2}{|c|}{ Emergency shutdown }} & Insertion of safety plates & Insertion of safety plates \\
\hline & & Drain of fuel solution & Drain of light water moderator \\
\hline \multicolumn{2}{|c|}{ Shutdown margin } & $<0.985$ in $k_{\text {eff }}$ & $<0.985$ in $k_{\text {eff }}$ \\
\hline \multicolumn{2}{|c|}{ One-rod stuck margin } & $<0.995$ in $k_{\text {eff }}$ & $<0.995$ in $k_{\text {eff }}$ \\
\hline
\end{tabular}




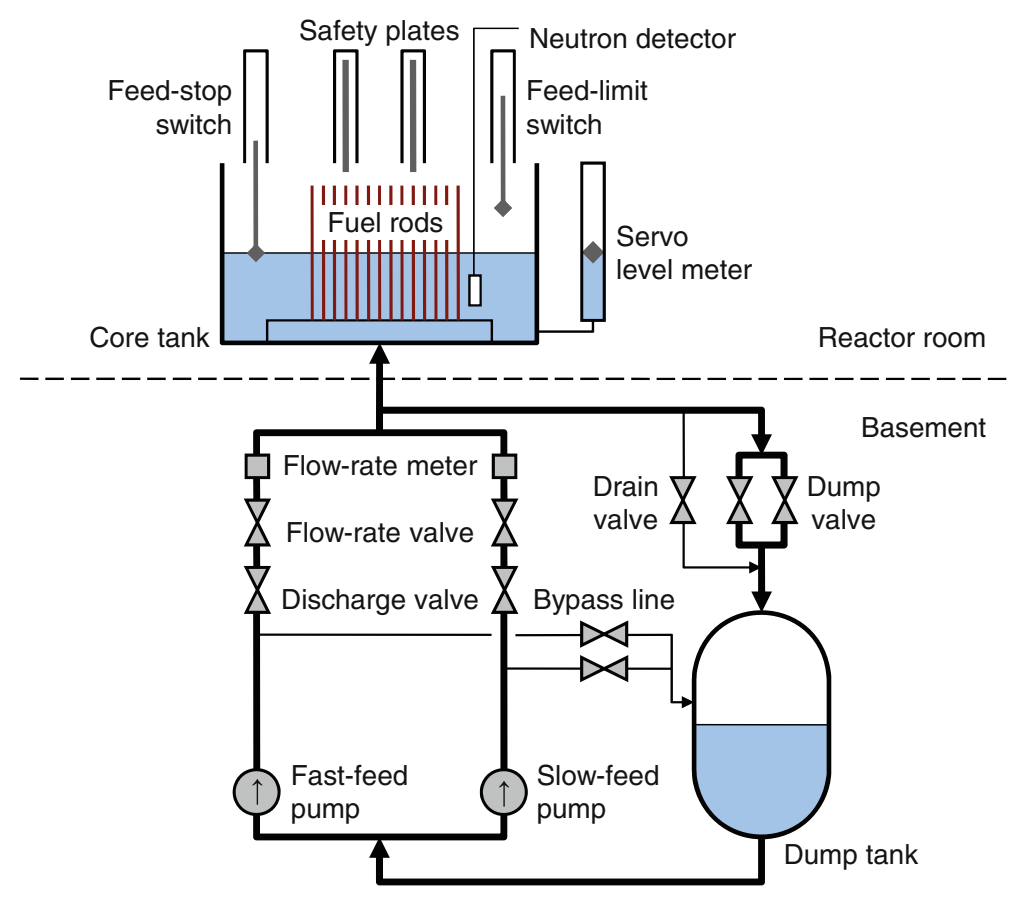

Fig. 22.1 Schematic diagram of the modified Static Experiment Critical Facility (STACY)

\subsubsection{Critical Experiments on Criticality Safety for Fuel Debris}

The JAEA research program includes computation of criticality characteristics covering a wide range of fuel debris conditions and validation of the computation by critical experiments. In the former activity, several data sets will be systematically obtained by calculation to establish new criticality safety standards for fuel debris. The new standards will be provided as "criticality maps" that indicate subcritical and critical conditions. The maps also show supercritical conditions that would likely lead to a significant threat of human injury [7]. In the latter activity, the new standards (including computation models) will be validated regarding reactivity worth, coefficients of reactivity, and critical mass by critical experiments with simulated fuel debris samples. A criticality monitoring methodology will also be studied to improve the criticality control measures for fuel debris.

To pursue the aforementioned critical experiments, the core of the modified STACY has a widely distributed neutron energy spectrum between thermal reactor spectra and intermediate reactor spectra. The neutron energy spectrum of the core can be varied by the lattice pitch of the fuel rods, which range from 10.9 to $25.5 \mathrm{~mm}$, corresponding to a moderator-to-fuel volume ratio ranging from 0.9 to 11 . Typical neutron energy spectra of the modified STACY are shown in Fig. 22.2 [8]. 


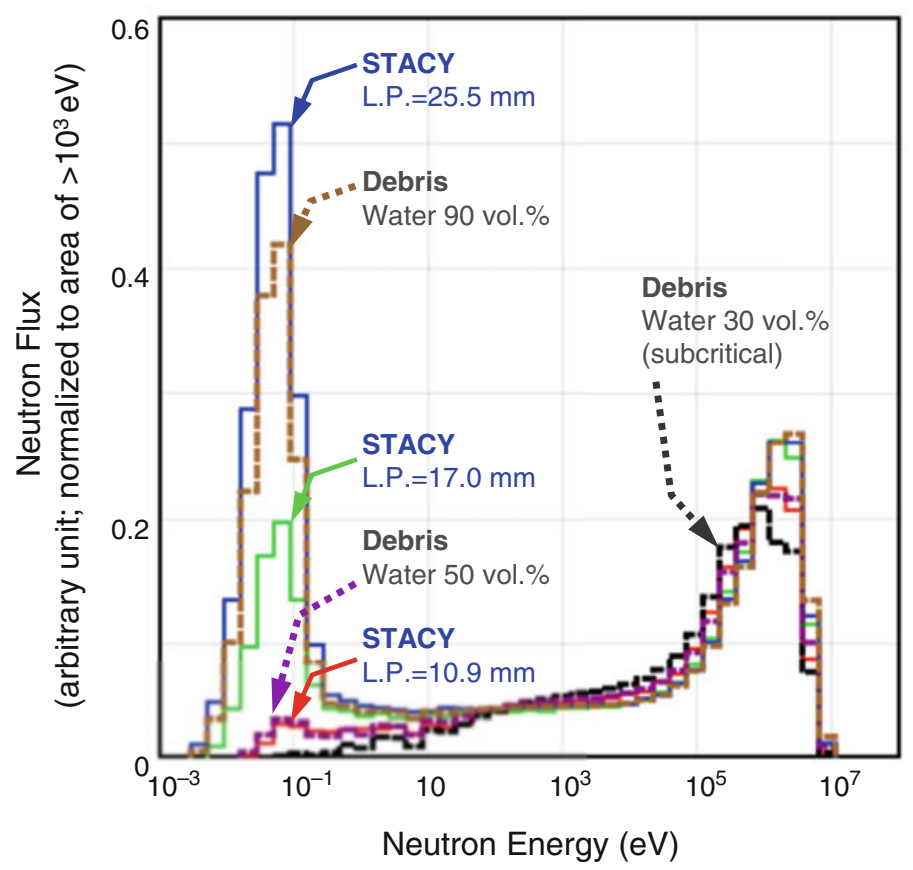

Fig. 22.2 Neutron energy spectrum of the modified STACY core

This figure also shows typical spectra of hypothetical fuel debris of a BWR fuel pellet (3.7 wt.\% ${ }^{235} \mathrm{U}, 27.5 \mathrm{GWd} / \mathrm{t}$, 5-year-cooled), for comparison. Both spectra were calculated using a burn-up code, ORIGEN2 [9], and a Monte Carlo code, MVP2 [10], with a nuclear data library, JENDL-3.3 [11]. It can be seen in Fig. 22.2 that the core spectrum with a lattice pitch of $10.9 \mathrm{~mm}$ is equivalent to the debris spectrum in 50 vol.\% water. The core spectrum of the modified STACY can cover relatively hard spectra of the fuel debris likely to become critical.

For the measurement of the neutronic characteristics of fuel debris, two sets of experimental equipment should be prepared: one includes reactor material structures simulating fuel debris (zircaloy, stainless steel, concrete, etc.), which are pin-, plate-, or box type and are loaded between fuel rods. The other is a sample-loading device to measure its reactivity and which is installed at a test region in the core tank. The experimental equipment is shown in Fig. 22.3.

\subsubsection{Manufacturing and Analytical Equipment for Simulated Fuel Debris Samples [12]}

The simulated fuel debris samples (sintered pellets) are to be manufactured by mixing $\mathrm{UO}_{2}$ and reactor structural materials ( $\mathrm{Zr}, \mathrm{Fe}, \mathrm{Si}, \mathrm{Gd}, \mathrm{B}$, etc.) with various chemical compositions. These debris materials will be mixed in the form of oxide 


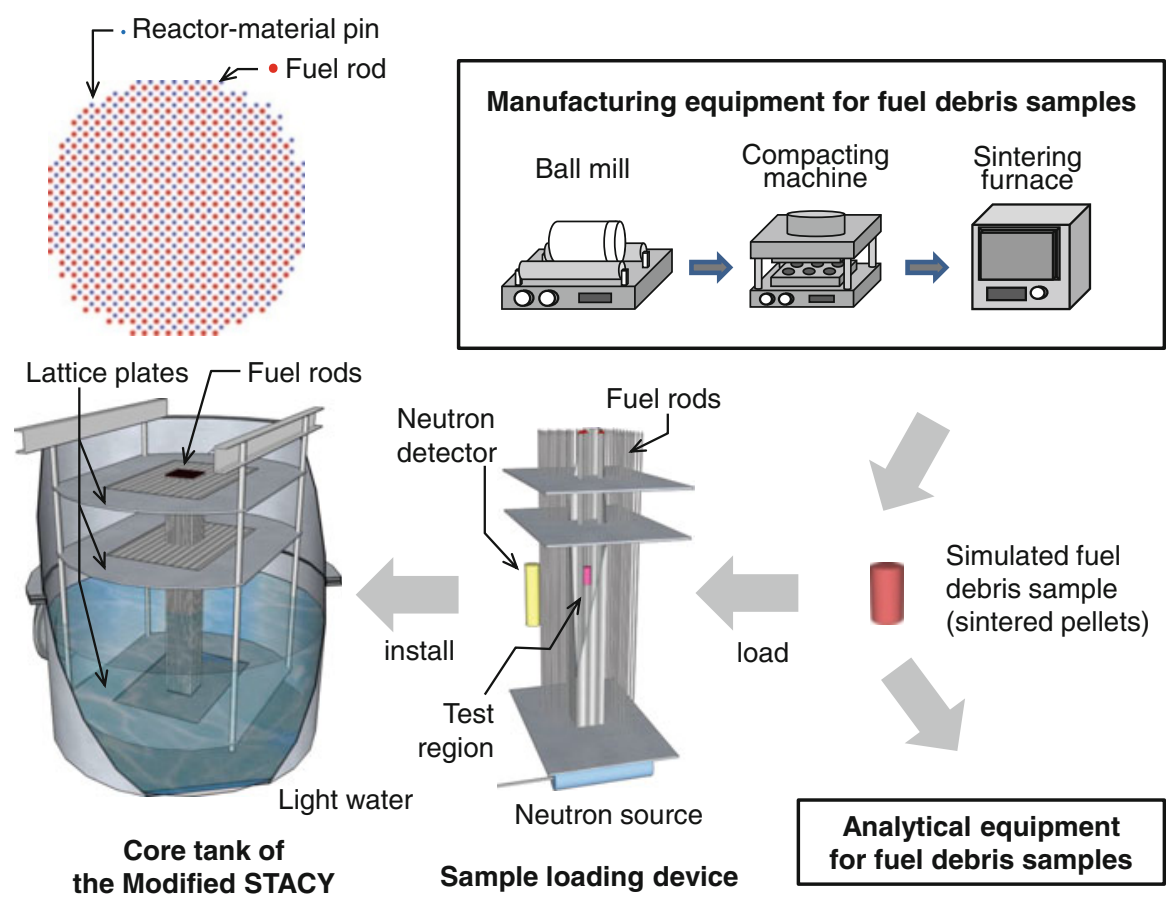

Fig. 22.3 Experimental equipment for simulated fuel debris samples

powders. The manufacturing equipment for the debris samples is composed of a ball mill, compacting machine, and sintering furnace. The debris samples will be analyzed destructively or nondestructively to determine nuclide composition, $\mathrm{O} / \mathrm{U}$ ratio, density, and impurities. The manufacturing ability is to be 300 pellets a month. The analytical precision is still a matter under consideration. The manufacturing and analytical equipment are to be installed in glove boxes in the experimental building adjoining the modified STACY.

\subsection{License Application and Schedule of the STACY Modification}

The license application for the STACY modification was sent in February 2011 and has been under safety review by the Nuclear Regulation Authority (NRA) of Japan to comply with new safety standards for research reactors enforced in December 2013 [13]. In particular, the NRA will strictly demand prevention measures against natural disasters such as a tsunami from all reactors located at a low altitude. The modified STACY, the reactivity of which is controlled by water level, has a risk of criticality accidents for the duration of tsunami attacks. The prevention measures 


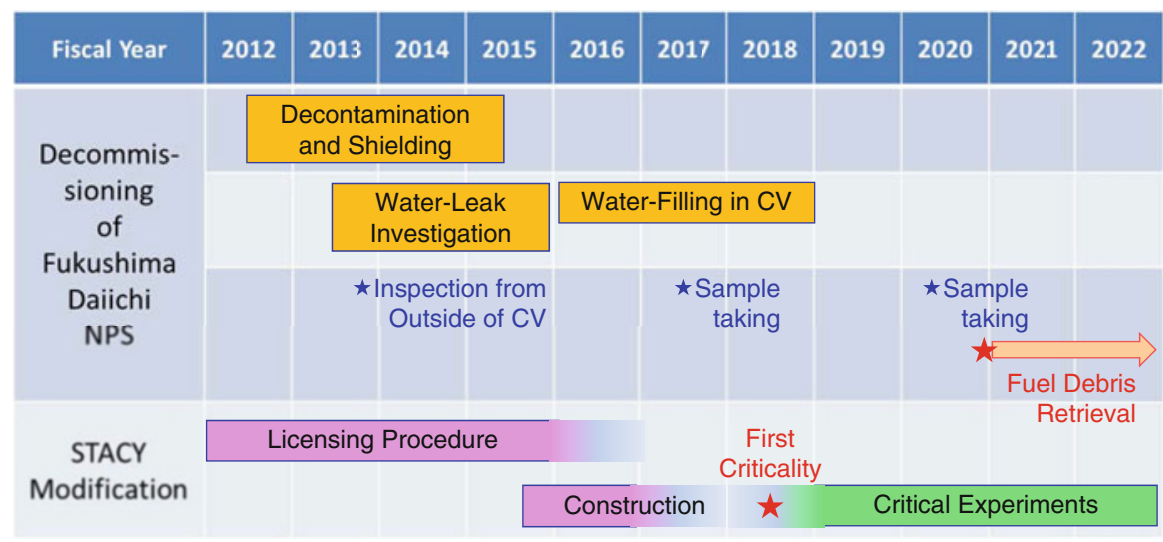

Fig. 22.4 Schedule of the STACY modification. $C V$ containment vessel

against criticality accidents are important requirements for the modified STACY: for example, limitation of the core configuration together with the safety plates inserted so as to keep a subcritical state during submersion.

A schedule of the STACY modification is shown in Fig. 22.4. The first criticality experiment in the modified STACY is scheduled for 2018. The modified STACY will provide benchmark data on criticality safety for fuel debris to validate the criticality control measures applicable to the Fukushima Daiichi NPS. The new criticality control measures need to be established by the time the fuel debris begins to be retrieved from each reactor unit of the Fukushima Daiichi NPS. According to the governmental council, retrieval of the fuel debris is scheduled to start as early as 2020 , depending on the progress in the decommissioning of each reactor unit [2].

\subsection{Concluding Summary}

For the decommissioning of the Fukushima Daiichi Nuclear Power Station Units 1,2 , and 3 , research and development activities have been pursued to retrieve fuel debris from the pressure and containment vessels of each reactor unit. In preparation for the retrieval, however, there remain serious problems concerning the cooling water of fuel debris from the aspect of criticality safety.

To study the new criticality control measures for the fuel debris, the Japan Atomic Energy Agency has carried forward a project to modify the Static Experiment Critical Facility (STACY) and to pursue critical experiments regarding the fuel debris. STACY, a facility using solution fuel, is to be converted into a thermal critical assembly using fuel rods and a light water moderator. A series of critical experiments will be conducted in the modified STACY using simulated fuel debris samples. These samples are to be manufactured by mixing $\mathrm{UO}_{2}$ and reactor structural materials with various chemical compositions. 
The license application for the STACY modification has been under safety review. The first criticality experiment in the modified STACY is scheduled for 2018. The modified STACY will provide benchmark data on criticality safety for fuel debris to validate the new criticality control measures applicable to the Fukushima Daiichi Nuclear Power Stations.

Open Access This chapter is distributed under the terms of the Creative Commons Attribution Noncommercial License, which permits any noncommercial use, distribution, and reproduction in any medium, provided the original author(s) and source are credited.

\section{References}

1. Tokyo Electric Power Company, Inc. (2012) Fukushima nuclear accident analysis report

2. Nuclear Emergency Response Headquarters, Council for the Decommissioning of TEPCO's Fukushima Daiichi Nuclear Power Station (2013) Mid- and-long-term roadmap towards the decommissioning of TEPCO's Fukushima Daiichi nuclear power station unit 1-4

3. Stratton WR (1987) Review of the state of criticality of the Three Mile Island unit 2 core and reactor vessel. DOE/NCT-01. Lawrence Livermore National Laboratory

4. Izawa $\mathrm{K}$ et al (2012) Infinite multiplication factor of low-enriched $\mathrm{UO}_{2}$-concrete system. J Nucl Sci Technol 49(11):1043

5. Tonoike K et al (2013) Major safety and operational concerns for fuel debris criticality control. In: Proceedings of the GLOBAL 2013: international nuclear fuel cycle conference, Salt Lake City, September 29-October 3, 2013

6. Miyoshi Y (2013) STACY modification program and critical experiments using pseudo fuel debris. Working party on nuclear criticality safety, October 11, 2013, OECD/NEA, Paris

7. Tonoike K et al (2013) Principle options of fuel debris criticality control in Fukushima Daiichi Reactors. In: International symposium on nuclear back-end issues and the role of nuclear transmutation technology after the accident of TEPCO's Fukushima Daiichi Nuclear Power Stations, Kyoto, November 28, 2013

8. Izawa K et al (2012) Feasibility study on critical experiment with fuel debris in modified STACY. 3. Neutronic characteristics analysis of modified STACY core. In: Proceedings of the annual meeting of AESJ, Fukui, March 19-21, 2012, E37 (in Japanese)

9. Croff AG (1980) ORIGEN2: a revised and updated version of the Oak ridge isotope generation and depletion code. ORNL-5621. Oak Ridge National Laboratory

10. Nagaya $Y$ et al (2005) MVP/GMVP II: general purpose Monte Carlo codes for neutron and photon transport calculations based on continuous energy and multigroup methods. JAERI1348. Japan Atomic Energy Research Institute

11. Shibata K et al (2002) Japanese evaluated nuclear data library, version 3, revision 3: JENDL3.3. J Nucl Sci Technol 39(11):1125-1136

12. Umeda $M$ et al (2012) Feasibility study on critical experiment with fuel debris in modified STACY. 2. Fabrication and analyses of pseudo fuel debris at nuclear fuel usage facility in NUCEF. In: Proceedings of the annual meeting of AESJ, Fukui, March 19-21, 2012, E36 (in Japanese)

13. Kida T et al (2013) Evaluation of nuclear characteristics and safety design examination of modified STACY for critical experiments on fuel debris. 1. Outline of critical experiments on fuel debris and safety design principle. In: Proceedings of the annual meeting of AESJ, Higashi-Osaka, March 26-28, 2013, H30 (in Japanese) 